\title{
MANIPUEIRA EM PÓ: ESTUDO PIONEIRO SOBRE SUA AÇÃO COMO FUNGICIDA E FERTILIZANTE FOLIAR
}

\author{
Erbene Góes ${ }^{1}$ \\ J. Júlio da Ponte ${ }^{2}$
}

\section{RESUMO}

A manipueira em pó (produto recém-formulado e ainda em fase de registro de patente) foi preliminarmente testada em amendoim (Arachis hipogaea), como fungicida - no controle de Mycosphaerella arachidicola, agente causal da Mancha Castanha - e fertilizante foliar. Em seu estado natural, a manipueira é o extrato líquido das raízes de Manihot esculenta, um subproduto da farinha de mandioca. O experimento foi conduzido em condições de campo, em delineamento inteiramente casualizado, com 25 plantas (parcelas) por tratamento. Eis os tratamentos: T1 - manipueira em pó, 1 colher de sopa para $1 \mathrm{~L}$ de água; T2 - manipueira em pó, 2 colheres de sopa para $1 \mathrm{~L}$ de água; T3 - manipueira líquida, diluída em água (50\%), e T4 - somente água (testemunha). Cada tratamento foi aplicado seis vezes, em pulverizações a intervalos semanais. A incidência da Mancha Castanha nas plantas tratadas com manipueira em pó foi praticamente nula, mas o baixo índice de ataque do fungo nas plantas testemunhas não permitiu uma avaliação mais segura da ação fungicida do composto. Todavia, os efeitos da manipueira em pó como adubo foliar foram bem evidentes, aumentando, de um modo estatisticamente significativo, a produção (em peso total das vagens) e o porte vegetativo (peso fresco) das plantas de amendoim.

1 Bolsista da FUNCAP (Fundação Cearense de Apoio ao Desenvolvimento Científico e Tecnológico); Pesquisadora da Clínica de Planta Dr. Júlio da Ponte, rua Teresa Cristina, 184, 60015-140 Fortaleza-CE.

2 Universidade Federal do Ceará, Dep. de Fitotecnia-Fitossanidade, Caixa Postal 12168, 60356-001 Fortaleza-CE. Membro da Academia Cearense de Ciências. 
Palavras-chave: manipueira em pó, controle, pesticida natural, fertilizante foliar natural.

\section{ABSTRACT \\ MANIPUEIRA POWDER: PRELIMINARY STUDY ON ITS FUNGICIDE AND FOLIAR NUTRIENT ACTIONS}

Manipueira powder (a product recently formulated and with patent registration in progress) was preliminary tested on Arachis hypogaea against the peanut leaf spot (Mycosphaerella arachidicola). Manipueira is a cassava by-product (liquid extract - a subproduct of the industrialization of Manihot esculenta roots). The field experiment was set up in a completely randomized design, with 25 plants (plots) per treatment. Treatments were as follows: $\mathrm{T} 1$ - one soup spoon of the powder in $1 \mathrm{~L}$ of water; $\mathrm{T} 2$ - two soup spoon of the powder in $1 \mathrm{~L}$ of water; $\mathrm{T} 3-$ liquid manipueira in water $(1: 1 \mathrm{v} / \mathrm{v})$ and T4 - Control (pure water). Plants were sprayed 6 times, weekly. Due to the low natural fungus infection during the experimental period, the fungicide action of manipueira could not be successfully assessed. However, the manipueira influence as foliar nutrient was statistically significant concerning the plant production (total pod weight) and fresh weight of sprayed plants, compared with control ones.

Key words: manipueira powder, control, natural pesticide, natural foliar fertilizer.

\section{INTRODUÇÃO}

A manipueira é o extrato líquido das raízes de mandioca (Manihot esculenta Crantz), fluente por ocasião da prensagem, durante o processamento da farinha. Portanto, é um subproduto da farinha de mandioca e, a exemplo desta, abundante em todas as regiões de cultivo e industrialização da citada planta.

Objeto de um projeto em curso na Universidade Federal do Ceará 
(Brasil) - Utilização da Manipueira como Defensivo e Fertilizante Agrícolas -, implementado há mais de vinte anos (Ponte et al., 1979), a manipueira foi testada como nematicida, inseticida, fungicida, acaricida e fertilizante foliar (nesta ordem), com respostas positivas para todas essas finalidades (Ponte, 1999). Apesar da excelência de tais resultados, o uso da manipueira apresenta duas limitações: a sazonalidade (no Nordeste, a maioria das casas de farinha não funciona na estação das chuvas) e a perecibilidade do composto, cuja ação pesticida vai declinando a partir do quarto dia (Ponte \& Franco, 1983).

A fim de anular tais inconvenientes, e prover maiores facilidades de transporte e comercialização, os autores passaram a produzir a manipueira em pó (Ponte \& Góes, 2002), produto ainda em fase de registro de patente, cuja composição química preservou todos os nutrientes e ingredientes pesticidas (i.a.) existentes na manipueira natural (líquida), consoante análise feita pelos citados autores.

Neste trabalho, a manipueira em pó é testada, pela primeira vez, como fungicida, no controle do fungo Mycosphaerella arachidicola W.A. Jenkins, agente da Mancha-Castanha, e como fertilizante foliar, com o amendoim (Arachis hypogaea L.) como planta-teste.

\section{MATERIAL E MÉTODOS}

O experimento foi conduzido no período de setembro a dezembro de 2001, junto ao Setor de Horticultura do Centro de Ciências Agrárias da Universidade Federal do Ceará, em Fortaleza, Estado do Ceará, Brasil. Considerando a homogeneidade edáfica (latossolo amarelo) do canteiro que serviu de área experimental, optou-se por um delineamento inteiramente casualizado.

$\mathrm{O}$ experimento reuniu quatro tratamentos: $\mathrm{T} 1$ - manipueira $\mathrm{em}$ pó, na dosagem de 1 colher de sopa $(20 \mathrm{~g})$ por litro de água; T2 manipueira em pó, na dosagem de 2 colheres de sopa (40g) por litro de água; T3 - manipueira líquida (natural), em diluição aquosa 1:1, e T4 água (testemunha). As dosagens do primeiro e segundo tratamentos correspondem, respectivamente, à manipueira natural em diluição aquosa $1: 1(50 \%)$ e à manipueira natural pura $(100 \%)$. Para efeito de melhor 
aderência, acrescentou-se $1 \%$ de farinha de trigo às diluições do composto e, também, à água utilizada na testemunha. Os tratamentos foram ministrados em seis pulverizações a intervalos semanais, a partir do $35^{\circ}$ dia de idade das plantas.

Em cada tratamento, figuraram 25 plantas (parcelas) de amendoim cv. 57-422, distribuídas em cinco linhas de cultivo (repetições) com igual número de covas, espaçadas de $0,10 \mathrm{~m}$. Entre linhas, o espaçamento foi de $0,50 \mathrm{~m}$. Semearam-se três sementes por cova, procedendo-se ao desbaste 15 dias após a germinação, mantendo-se, então, uma única planta por cova. As plantas foram irrigadas, diariamente, por micro-aspersão.

O período experimental prolongou-se por todo o ciclo da cultura (120 dias), ao fim do que se avaliaram a ação fungicida do composto sobre o fungo $M$. arachidicola (agente causal da Mancha Castanha do amendoim) e sua eficiência como fertilizante foliar. Mediu-se o primeiro parâmetro em função do porcentual de plantas atacadas e do grau de severidade da doença, consoante uma escala de notas variável de zero (sem ataque) a cinco (ataque muito severo), conforme pontuação análoga aplicada por Muniz (1985). O segundo parâmetro foi aferido mediante, também, duas variáveis: desenvolvimento vegetativo (avaliado pelo peso fresco das plantas) e produção (peso total de vagens). Estes dados foram analisados estatisticamente (análise da variância e teste de Tukey), usando-se 5\% como limite de significância estatística.

$\mathrm{Na}$ determinação do peso fresco, considerou-se a planta por inteiro, a exceção das vagens.

\section{RESULTADOS E DISCUSSÃO}

Na Tabela 1, estão expostos os dados pertinentes à incidência do fungo M. arachidicola (Mancha Castanha), nas plantas de amendoim submetidas aos diversos tratamentos testados. Observa-se que, nos tratamentos T1 e T2, relativos às duas dosagens de manipueira em pó (1 e 2 colheres de sopa, respectivamente), a ocorrência da doença foi praticamente nula: $0,5 \% \mathrm{em}$ ambos os casos. No tratamento com manipueira natural (T3), a percentagem de plantas atacadas foi de $2 \%$, enquanto no tratamento-testemunha este percentual subiu para $3 \%$. Em todos os trata- 
Tabela 1. Porcentagem de ocorrência da Mancha Castanha (Mycosphaerella arachidicola) nas plantas de amendoim, Arachis hypogaea, que integraram o experimento pertinente à avaliação da manipueira em pó como defensivo e fertilizante agrícolas.

\begin{tabular}{c|c} 
Tratamentos & Médias* (\%) \\
\hline $\begin{array}{c}\text { T1 } \\
\text { Manipueira em pó: } 1 \text { colher de sopa por litro }\end{array}$ & 0,5 \\
\hline T2 & 0,5 \\
Manipueira em pó: 2 colheres de sopa por litro & 2,0 \\
T3 \\
Manipueira natural (líquida): em diluição aquosa 1:1 \\
T4 \\
Água (testemunha)
\end{tabular}

* Médias de 25 plantas por tratamento. Grau de severidade da doença $=1$ (em todos os tratamentos), conforme a seguinte escala de notas: $0=$ sem ataque; $1=$ ataque muito fraco; $2=$ ataque fraco $3=$ moderado $; 4=$ severo, e $5=$ muito severo.

mentos, todavia, a incidência da doença foi muito fraca (nota 1). Assim, os baixos percentuais da doença e, sobretudo, o caráter muito leve de sua incidência, não permitiram, neste ensaio, uma avaliação mais segura sobre uma provável ação fungicida da manipueira em relação ao citado fungo, ação que já foi constatada para fungos dos grupos dos oídios e das ferragens, por Santos \& Ponte (1993) e Pontes \& Góes (2000), respectivamente.

Por outro lado, a eficiência da manipueira em pó como adubo foliar ficou claramente demonstrada, especialmente na dosagem de $40 \mathrm{~g}$ por litro (tratamento T2), que induziu desenvolvimento vegetativo e produção estatisticamente superiores à da testemunha, conforme o exposto nas Tabelas 2 e 3 . O tratamento com manipueira em pó, na dosagem de $20 \mathrm{~g}$ por litro, bem assim o tratamento com manipueira natural, na dosagem de $1: 1$, também superaram a testemunha em peso fresco da planta e peso total de vagens, mas não de forma estatisticamente significativa. 
Tabela 2. Efeitos da manipueira, nas formas líquida (natural) e em pó, sobre o desenvolvimento vegetativo (peso fresco) e a produção (peso total dos frutos) de plantas de amendoim, Arachis hypopaea. Valores expressos em $\mathrm{kg}$.

\begin{tabular}{|c|c|c|}
\hline Tratamentos & Parâmetros & Médias \\
\hline $\begin{array}{c}\mathrm{T} 1 \\
\text { Manipueira em pó: } 1 \text { colher de sopa por litro }\end{array}$ & $\begin{array}{l}\text { Peso fresco } \\
\text { Peso total dos frutos }\end{array}$ & $\begin{array}{l}1,536 \mathrm{ab} \\
0,395 \mathrm{ab}\end{array}$ \\
\hline $\begin{array}{c}\text { Manipueira em pó: } 2 \text { colheres de sopa por } \\
\text { litro }\end{array}$ & $\begin{array}{l}\text { Peso fresco } \\
\text { Peso total dos frutos }\end{array}$ & $\begin{array}{l}1,846 \mathrm{a} \\
0,507 \mathrm{a}\end{array}$ \\
\hline $\begin{array}{c}\text { T3 } \\
\text { Manipueira natural (líquida): em diluição } \\
\text { aquosa 1:1 }\end{array}$ & $\begin{array}{l}\text { Peso fresco } \\
\text { Peso total dos frutos }\end{array}$ & $\begin{array}{l}1,546 a b \\
0,412 a b\end{array}$ \\
\hline $\begin{array}{c}\text { T4 } \\
\text { Água (testemunha) }\end{array}$ & $\begin{array}{l}\text { Peso fresco } \\
\text { Peso total dos frutos }\end{array}$ & $\begin{array}{l}1,186 b \\
0,330 \mathrm{~b}\end{array}$ \\
\hline Fcalc. $($ a $5 \%)=3,24$ & \multicolumn{2}{|c|}{$\begin{array}{l}\text { Peso fresco: } F=4,05 \text { e C.V. }=39,47 \% \\
\text { Peso frutos: } F=3,29 \text { e C.V. }=39,53 \%\end{array}$} \\
\hline
\end{tabular}

Obs.: Médias seguidas das mesmas letras não diferem, estatisticamente, entre si, ao nível de $5 \%$ de probabilidade.

Todavia, se observa uma tendência neste sentido, o que provavelmente teria acontecido caso se utilizasse um número maior de repetições e não fosse tão elevado o coeficiente de variação (acima de 39\%).

Esses primeiros resultados com manipueira em pó - produto ainda em processo de reconhecimento de patente - são muito animadores, mostrando que a nova formulação do composto não lhe comprometeu a eficácia como defensivo e fertilizantes agrícolas, como, aliás, já se podia antever à luz dos resultados indicados pela prévia análise de sua composição química, semelhante à da manipueira líquida em seu estado natural (Ponte \& Góes, 2002).

\section{CONCLUSÃO}

A manipueira em pó, em sua primeira avaliação como adubo foliar, revelou a mesma eficiência demonstrada pela manipueira natural (estado 
líquido) em experimentos anteriores. Todavia, a sua provável eficiência como fungicida, no controle do agente causal da Mancha Castanha do amendoim, carece de uma avaliação mais segura, em razão dos baixos índice de incidência do patógeno ( $M$. arachidicola) neste experimento.

\section{REFERÊNCIAS BIBLIOGRÁFICAS}

MUNIZ, J.O.L., 1985. Cultivares Resistentes e Fungicidas no Controle da Queima das Folhas da Cenoura, na Serra de Baturité, Ceará. Fortaleza: UFC, 72p. (Tese de Mestrado, Universidade Federal do Ceará).

PONTE, J.J. da, 1999. Cartilha da Manipueira, Uso do Composto como Insumo Agrícola. Fortaleza: SECITECE, 53p.

PONTE, J.J. da \& FRANCO, A., 1983. Influência da Idade da Manipueira na Preservação do Potencial Nematicida do Composto. Publ. Soc. Bras. Nematol., Piracicaba, v. 7, p. 237-240.

PONTE, J.J. da \& GÓES, E., 2002. Composição Química da Manipueira em Pó. Anais Congr. Bras. Def. Agr. Naturais, Fortaleza, v. 2, p. 1. (Resumo).

PONTE, J.J. da \& GÓES, E., 2000. Investigação Preliminar Envolvendo a Manipueira no Controle de Ferrugem. Anais Congr. Bras. Def. Agr. Naturais, Fortaleza, v. 1, p. 39. (Resumo).

SANTOS, A.B.C. \& PONTE, J.J. da, 1993. Ação Fungicida da Manipueira no Controle de Oídio. Fitopatol. bras., Brasília, v. 18, p. 302-303. 